\title{
Kajian Nilai Pendidikan Karakter Dalam Novel Tapak Jejak Karya Fiersa Besari
}

\author{
Sunggi Murniasih ${ }^{1}$, Dwi Gusti Yolanda ${ }^{2}$, Cintya Nurika Irma ${ }^{3}$ \\ ${ }^{123}$ Pendidikan Bahasa Indonesia, FKIP, Universitas Peradaban ${ }^{123}$ \\ e-mail: murniasih1218@gmail.com ${ }^{1}$,dwigustiyolanda@gmail.com ${ }^{2}$, Cintya_nurikairma@yahoo.co.id ${ }^{3}$
}

\begin{tabular}{ccc}
\hline Diterima & Direvisi & Disetujui \\
$22-01-2021$ & $14-03-2021$ & $31-03-2021$ \\
\hline
\end{tabular}

\begin{abstract}
Abstrak - Karya sastra merupakan bentuk kegiatan kreatif dan produktif dalam menghasilkan sebuah karya sastra yeng memiliki nilai rasa estetis serta mencerminkan realitas sosial kemasyarakatan. Novel merupakan salah satu karya sastra yang banyak mengaandung nilai pendidikan karakter. Salah satu nilai dalam sebuah karya sastra yang dapat digunakan sebagai bahan pembelajaran yaitu nilai pendidikan karakter. Tujuan utama pendidikan karakter adalah untuk membangun bangsa yang tangguh, di mana masyarakatnya berakhlak mulia, bermoral, bertoleransi, dan bergotong royong. Penelitian ini bertujuan untuk mendeskripsikan nilai pendidikan karakter yang terdapat dalam novel Tapak Jejak karya Fiersa Besari. Analisis menggunakan pendekatan psikologi sastra. Metode yang digunakan dalam penelitian ini adalah metode narative deskriptif. Teknik pengumpulan data yang digunakan teknik baca dan teknik catat. Teknik validitas data dalam penelitian ini dengan triangulasi data. Teknik triangulasi yang dilakukan triangulasi sumber, triangulasi teori, dan triangulasi metode. Berdasarkan hasil analisis tersebut, diperoleh nilai pendidikan karakter yang terkandung dalam novel Tapak Jejak karya Fiersa Besari, meliputi (1) religius dalam bentuk toleransi beragama (2) jujur dimunculkan saat merasa nyaman di rumah yang lebih sederhana dari rumah sebelumnya, (3) kreatifitas dilakukan mengabadikan foto hewan di kelilingnya untuk mengatasi ketakutan adanya angin kencang, (4) semangat kebangsaan diwujudkan memerdekakan Indonesia dengan pembuktian tindakan bukan hanya secara lisan, (5) cinta tanah air dilakukan dengan upacara bendera yang mereka lakukan ketika berada di puncak Gamalama, (6) komunikatif ditunjukkan dengan mudahnya beradaptasi dengan orang yang baru dikenal, dan (7) cinta damai tampak pada sikap menghargai berbagai etnis.
\end{abstract}

Kata kunci: pendidikan karakter, novel, tokoh utama

Abstract- Literary work is a form of creative and productive activity in producing a literary work that has an aesthetic value and reflects social reality. Novel is one of the literary works that contains a lot of character education value. One of the values in a literary work that can be used as learning material is the value of character education. The main objective of character education is to build a strong nation, where people have noble, moral, tolerant, and cooperative values. This study aims to describe the value of character education contained in the novel Tapak Jejak by Fiersa Besari. The analysis uses a literary psychology approach. The method used in this research is descriptive narrative method. Data collection techniques used reading techniques and note-taking techniques. The data validity technique in this study was data triangulation. The triangulation technique used source triangulation, theory triangulation, and method triangulation. Based on the results of this analysis, the character education value contained in the novel Tapak Jejak by Fiersa Besari includes (1) being religious in the form of religious tolerance (2) being honest when feeling comfortable in a house that is simpler than the previous one, (3) creativity is carried out immortalize photos of animals around him to overcome the fear of strong winds, (4) the spirit of nationality is manifested to liberate Indonesia by proving actions not only verbally, (5) love for the country is carried out with a flag ceremony which they perform when they are at the top of Gamalama, (6) communicative is shown to easily adapt to new people, and (7) peace-loving is shown in respect for various ethnicities.

Keywords: character education, novel, main character

\section{PENDAHULUAN}

Karya sastra muncul karena adanya keinginan dari pengarang untuk mengungkapkan ide-ide atau imajinasi yang menarik tentang persoalan-persoalan disekitar yang diamatinya. Karya sastra merupakan media yang efisien untuk mengajarkan segala sesuatu seperti sains, nilai moral, nilai budi pekerti, dan nilai agama. Karya sastra berusaha menyampaikan nilainilai pendidikan yang merupakan refleksi dari kehidupan nyata sebagai bagian dari renungan kenyataan kehidupan yang dilihat (Febriana, Noni., Effendi, Harris., Thahar. 2014). 
Pendidikan karakter merupakan aset terpenting dalam kehidupan manusia untuk membentuk karakter peserta didik (Yulianto, Agus., Nuryati, Iis. 2020). Pendidikan karakter bukan hanya sekedar memberikan definisi tentang yang baik dan yang buruk, melainkan sebagai upaya mengubah sifat, watak, kepribadian dan keadaan batin manusia sesuai dengan nilai-nilai yang dianggap luhur dan terpuji.

Melalui pendidikan karakter ini diharapkan dapat dilahirkan manusia yang memiliki kebebasan menentukan pilihannya, tanpa paksaan dan penuh tanggung jawab.Yaitu manusia-manusia yang merdeka, dinamis, kreatif, inovatif, dan bertanggung jawab, baik terhadap Tuhan, manusia, masyarakat, maupun dirinya sendiri. Pendidikan berkarakter adalah pendidikan budi pekerti plus, yaitu melibatkan aspek pengetahuan (cognitive), perasaan (feeling), dan tindakan (action).

Nurgiyantoro $(2007,11)$ mengemukakan bahwa novel adalah bentuk karya sastra yang disebut fiksi. Novel ialah karya prosa yang berisi cerita yang melibatkan banyak tokok-tokoh di dalamnya dan memasukkan alur cerita satu kesatuan sebagai bagian dari keehidupan yang sangat jarang ada di dalam masyarakat (Pusvita, 2017). Nilai adalah kualitas suatu hal yang menjadikan hal itu disukai, diinginkan, dikejar, dihargai, berguna dan dapat membuat orang yang menghayatinya menjadi bermartabat.

Nilai selalu berhubungan dengan kebaikan, kebijakan, dan keluhuran budi, serta kian menjadi sesuatu yang dihargai, dijunjung tinggi, serta dikejar seseorang sehingga ia merasakan adanya suatu kepuasan dan ia merasa menjadi manusia sebenarnya. nilai-nilai pendidikan merupakan topik yang menarik dan senantiasa aktual untuk dijadikan acuan agar nilai-nila pendidikan dapat diterapkan dalam pembentukan prilaku pada saat ini (Elner, Thahar, Abdurahman, 2018).

Dalam novel terdapat nilai-nilai moral, religius, budaya, politik, sosial hingga pendidikan. Novel memberikan memberikan penanaman nilai-nilai moralitas dengan kata- kata yang memberikan interpretasi dan apersepsi tersendiri bagi pembacanya sehingga bagi anak-anak dengan membaca sastra novel selain dapat meningkatkan kecerdasan dan menanamkan nilai-nilai moralitas yang berasal dari dunia yang terbentuk dan terinterpretasikan dari katakata yang dibacanya sendiri (Wardani, Ana., Mawardi, Imam., Jannah, 2015).

Di dalam novel mengandung rangkaian cerita kehidupan seseorang atau diri sendiri yang menggambarkan watak dan sifat setiap pelaku. Pengarang di dalam sebuah novel biasanya berusaha semaksimal mungkin untuk memberikan arahan kepada pembaca untuk mengetahui pesan tersembunyi melalui sebuah cerita gambaran realita seseorang. Novel sebagai salah satu produk sastra yang memegang peranan penting di dalam memberikan berbagai kemungkinan menyikapi kehidupan.

Individu yang berkarakter baik bisa membuat keputusan dan mempertanggungjawabkan akibat dari keputusan yang telah dibuat. Ada 18 nilai pendidikan karakter yang termuat dalam Kementerian Pendidikan Nasional (Kementerian Pendidikan Nasional, 2011), yaitu: (1) religius, (2) jujur, (3) toleransi, (4) disiplin, (5) kerja keras, (6) kreatif, (7) mandiri, (8) demokratis, (9) rasa ingin tahu, (10) semangat kebangsaan, (11) cinta tanah air, (12) menghargai prestasi, (13) komunikatif, (14) cinta damai, (15) gemar membaca, (16) peduli lingkungan, (17) peduli sosial, (18) tanggung jawab (Ingsih, dkk. 2018). Pendidikan karakter adalah proses mendidikan yang dilakukan untuk tujuan-tujuan yang telah ditentukan.

Tujuan pendidikan karakter adalah sempurnanya hidup manusia sehingga bisa memenuhi segala keperluan hidup lahir dan batin yang kita dapat dari kodrat alam. Tujuan utama pendidikan karakter adalah untuk membangun bangsa yang tangguh, di mana masyarakatnya berakhlak mulia, bermoral, bertoleransi, dan bergotong royong. Karya sastra dapat menjadi media dalam implementasi pendidikan karakter (Irma 2018). Pendidikan karakter adalah nilai-nilai yang tertanam pada jiwa diri sendiri maupun dalam tindakannya mengambil keputusan yang beradab antar sesama manusia maupun dalam hubungannya dengan Tuhan Yang Maha Esa (Rosdiatun, 2018).

Novel ini menceritakan kisah perjuangan hidupnya dalam berpetualang. Novel ini erat kaitannya dengan pendidikan karakter sehingga novel dianggap penting sebagai media pewarisan nilai-nilai luhur. Nilai-nilai karakter yang terkandung dalam novel Tapak Jejak karya Fiersa Besari masih rendah dimiliki anak pada masa sekarang ini, Kurangnya nilai-nilai pendidikan karakter yang dimiliki anak pada masa sekarang, Pendidikan nilai-nilai karakter dianggap tidak penting oleh anak pada masa saat ini.

Kajian ini menggunakan novel Tapak Jejak merupakan karya Fiersa Besari terbitan 2019 (Besari 2019). Novel Tapak Jejak akan melanjutkan perjalanan Arah Langkah, mengunjungi daerahdaerah di wilayah timur Indonesia, menelusuri keindahan alam, budaya, dan tradisi. Menembus dinding kegelisahan akan makna keluarga dan rumah. Pendidikan dengan karakter tidak dapat dipisahkan. Untuk membangun karakter anak yang baik orang tua harus menyekolahan anak. Dengan adanya pendidikan karakter akan membentuk karakter yang baik untuk masa depan mereka. Banyak anak pada masa sekarang tidak memiliki karakter yang bagus, 
yang disebabkan pengaruh lingkungan atau pengaruh keluarga sehingga perilaku anak menyimpang menjadikan masa depan mereka hancur.

Sebuah karya sastra tersimpan nilai atau pesan yang berisi amanat atau nasihat yang diberikan oleh penulis untuk pembaca. Salah satu karya sastra yang memuat nilai-nilai pendidikan adalah novel Tapak Jejak Karya Fiersa Besari. Berdasarkan uraian di atas, rumusan masalah yang dapat ditentukan yaitu bagaimanakah nilai pendidikan karakter pada tokoh utama dalam novel Tapak Jejak? Adapun tujuan penelitiann ini adalah mendeskripsikan dan menjelaskan nilai-nilai pendidikan karakter pada tokoh utama dalam novel Tapak Jejak.

\section{METODE PENELITIAN}

Metode yang digunakan dalam penelitian ini adalah metode narative deskriptif. Teknik analisis dilakukan dengan langkah-langkah pengumpulan data dan membaca secara keseluruhan maupun sebagian novel Tapak Jejak. Subjek yang digunakan dalam penelitian ini adalah novel Tapak Jejak karya Fiersa Besari yang diterbitkan Mediakita cetakan pertama 2019, berisi 310 halaman. Data yang dilakukan dengan data triangulasi data dan teori. Teknik triangulasi yang dilakukan triangulasi sumber, triangulasi teori, dan triangulasi metode. Selanjutnya, teknik analisis dilakukan dengan langkah-langkah (a) pengumpulan data, (b) mengidentifikasi data, (c) mereduksi data, (d) penyajian data, (e) penarikan simpulan.

\section{HASIL DAN PEMBAHASAN}

Novel Tapak Jejak karya Fiersa Besari yang menceritakan tentang kisah perjalanan dan petualangannya. Fiersa Besari dibesarkan oleh ibunya yang bernama Lilis Yuliandini. Ia adalah anak kedua dari delapan bersaudara. Novel Tapak Jejak mengandung dua tema, yaitu tema pokok dan tema tambahan. Pertama, tema pokok yang terkandung dalam novel Tapak Jejak, yaitu perjuangan dalam meraih mimpi-mimpi ataupun prestasi oleh sang penulis. Kedua, tema tambahan yang terkandung dalam novel Tapak Jejak adalah kasih sayang dan kecintaan terhadap negeri Indonesia (Sipayung, N. N. S,. Lubis, R. S., Sibagariang, N., \& Matahari 2019). Berdasarkan hasil analisis terdapat tujuh nilai-nilai pendidikan karakter yang ditemukan dalam Novel Tapak Jejak karya Fiersa Besari yang diuraikan sebagai berikut:

\section{Religius}

Religius adalah sikap dan perilaku yang patuh dan menghargai terhadap agama lainnya. Karakter religius sangat penting dalam kehidupan manusia ataupun seseorang dan menjadi sikap hidup yang megacu pada larangan sikap yang telah diatur dalam aturan agamanya.

“Ajarkan aku tentang islam," ucap om Toy pada ibu pada suatu malam. Aku pernah mencuri dengar percakapan mereka. "Kita belajar bareng ya," sahut ibu yang dari nada bicaranya terdengar senang dengan niat om Toy (TJ, 2019: 47).

Pernyataan di atas menjelaskan bahwa om Toy yang sejak lahir dari keluarga Tionghoa menghargai perbedaan agama lain yaitu agama Islam yang dianut oleh ibu Fiersa Besari dan Satriya. Bahkan, om Toy pun bersedia jika berpindah agama dari Tionghoa menjadi agama Islam. Dalam hal ini dibuktikan bahwa om Toy ingin masuk ke dalam agama yang dianut oleh ibu Fiersa yaitu agama Islam mulai dengan cara mendengarkan ibu Fiersa mengajarkan tata cara sholat yang kemudian akan dipraktikannya dan juga akan belajar tentang islam yang lainnya.

\section{Jujur}

Jujur adalah perilaku yang menjadikan seseorang untuk bersikap jujur terhadap perkataan, perilaku maupun dalam pekerjaan. Perilaku jujur merupakan sikap menyatakan yang sebenar-benarnya tidak berbohong atau berkata hal-hal yang menyalahi apa yang terjadi.

Di Kopo, aku dan Satriya mendapat banyak teman baru. Dan, jujur saja, lama kelamaan, kami berdua merasa lebih betah di Kopo dibandingkan rumah kami yang dulu. Meski rumah ini kecil, meski kami hanya mengontrak di sini (aku tahu ini ketika curi-curi dengar lagi dari perbincangan ibu dengan om Toy), anakanak sebayaku sering bertandang dan bermain Nintendo di rumahku (TJ, 2019: 49).

Kutipan di atas menjelaskan bahwa ada perasaan yang jujur pada hati Fiersa dan Satriya terhadap rumah yang sekarang mereka tinggali, mereka merasa lebih betah selama di Kopo dibandingkan rumah mereka yang dulu. Adanya nilai jujur karena Fiersa dan Satriya merasakan hangatnya keluarga ketika pindah rumah di Kopo dibandingkan ketika mereka tinggal di rumah yang sebelumnya.

\section{Kreatif}

Kreatif adalah sesuatu yang dilakukan dan berpikir dalam suatu hal untuk menghasilkan cara atau menghasilkan sesuatu baru yang telah dimiliki. Kreatif juga dapat diartikan sebagai suatu kemampuan dalam menciptakan hal-hal baru atau 
cara-cara baru yang berbeda dari sesuatu yang sudah ada sebelumnya.

Satu elang bertengger dikejauhan, lalu terbang menangkap ikan. Satu elang lagi terbang kearah berlainan. Mereka seolah menari diudara. Tanpa memedulikan rintik gerimis yang membasahi kamera, kufoto sepasang elang yang sedang bertengger gagah itu. Laut sudah mulai tenang. Kami segera melanjutkan perjalanan karena takut angin kencang kembali menyerbu (TJ, 2019: 77).

Pada kutipan di atas membuktikan adanya nilai kreatif pada novel Tapak Jejak. Hal ini dibuktikan bahwa Fiersa memiliki sebuah kamera yang dia gunakan untuk mengabadikan suatu gambar yaitu sepasang elang yang sedang bertengger gagah itu.

\section{Semangat Kebangsaan}

Semangat kebangsaan adalah cara berpikir, bertindak, dan berwawasan yang mementingkan kemerdekaan bangsa dan negara di atas kepentingan diri sendiri. Semangat kebangsaan juga merupakan suatu keadaan yang menunjukkan adanya kesadaran untuk menyerahkan kesetiaan tertinggi dari setiap pribadi kepada negara.

Semoga kita bisa mencintai negeri ini bukan hanya dimulut saja. Semoga kita masih berniat untuk memerdekakan Indonesia untuk kesekian kalinya. Kali ini bukan dari penjajahan, tapi dari kemiskinan, kebodohan, dan ketimpangan. Semoga kita semua dapat merasakan kemerdekaan. Bukan merdeka untuk sewenangwenangan, tapi merdeka dari kesewenangwenangan (TJ, 2019: 27).

Kutipan di atas menjelaskan bahwa semangat kebangsaan dibuktikan pada semangat Fiersa dalam niatnya untuk memerdekakan Indonesia untuk kesekian kalinya. Fiersa menginginkan negara ini agar terbebas dari kemiskinan, kebodohan, dan ketimpangan. Fiersa pun berharap agar kita semua dapat merasakan kemerdakaan kembali. Hal ini dibuktikan dengan cara melakukan upacara bendera yang dilakukan oleh Fiersa dan pendaki lainnya.

\section{Cinta Tanah Air}

Cinta tanah air adalah sikap dan tindakan dalam mencintai bangsa sendiri dengan mengabdi dan berkorban, memelihara kesatuan dan persatuan, serta melindungi tanah air.

Jam ditangan sudah menunjukkan angka 11 saat kami memulai upacara. Puluhan orang tengah, termasuk aku, berbaris di lapangan luas tepat dihadapan puncak Gamalama. Kami menghadap bendera besar yang oleh 6 orang sudah dipegang dikejauhan, tepat di tebing dekat kawah.

"Hormat, gerak!" ucap pemimpin upacara, lantang (TJ, 2019: 25).

Berdasarkan kutipan tersebut, di atas menjelaskan bahwa adanya cinta tanah air pada diri Fiersa dan pendaki lainnya. Hal itu dibuktikan adanya kegiatan upacara bendera yang mereka lakukan ketika berada di puncak Gamalama. Upacara tersebut dilakukan bersama-sama tanpa memandang adanya perbedaan diantara mereka demi memelihara kesatuan dan persatuan serta melindungi tanah air.

\section{Komunikatif}

Komunikatif adalah suatu tindakan yang memperlihatkan suatu sikap dalam bergaul, rasa senang berbicara, dan berkerja sama dengan orang lain. Komunikatif yang baik yaitu komunikatif yang saling mudah dipahami dan dimengerti.

Baru lima belas menit berlalu, datang lagi seorang perempuan lainnya. Tubuhnya besar, rambutnya yang keriting ia kepang dengan model zig-zag bak artis hip-hop. Perempuan itu melempar senyum ramah kepadaku. Tanpa disuruh Sarah ia pun langsung memperkenalkan diri. Desi, namanya. Sarah berkata bahwa Desi adalah dosen bioteknologi di fakultas pertanian unipa. Logat Papua nya yang tidak lagi kental mengesankan ia sudah lama berada di luar Papua. Obrolan dan canda tawa membuat kami berempat cepat akrab. Sayangnya, Agu dan Desi terpaksa pamit tidur karena esok pagi harus bekerja (TJ, 2019: 9798).

Kutipan tersebut menjelaskan adanya nilai komunikatif pada novel Tapak Jejak. Hal itu dibuktikan adanya rasa senang berbicara, bergaul pada mereka. Meskipun dari mereka berempat ada yang baru kenalan tetapi tidak butuh waktu lama mereka pun cepat akrab. Fiersa mudah akrab dengan orang yang baru dikenalinya dengan saling memperkenalkan diri satu sama lain.

\section{Cinta Damai}

Cinta damai adalah sikap dan perilaku dalam menghargai suatu perbedaan yang dimiliki individu dan kelompok lain. Cinta damai juga merupakan suatu sikap atau tindakan yang menyebabkan orang lain merasa senang dan aman atas kehadiran dirinya.

Di kelas VI SD, kutemukan teman-teman baru yang tidak kalah seru dibandingkan sahabatsahabatku di Bandung. Apalagi, kota Jakarta yang terkenal dengan pendatangnya dari berbagai daerah. Jika di Bandung hampir 
semua temanku berasal dari latar Sunda, di sekolah yang baru bisa kutemukan anak-anak sebayaku dari etnis Batak, Jawa, Manado, bahkan ada satu orang dari Papua. Mereka cukup menyenangkan, dan selalu berdialog dengan aksen yang sama: aksen Betawi, lambat laun, aku jadi lupa caranya berbahasa Sunda (TJ, 2019: 90).

Kutipan di atas menjelaskan bahwa cinta damai dibuktikan pada Fiersa yang memiliki teman baru di sekolah barunya yang terdapat berbagai suku atau etnis yang ada di kelasnya yaitu dari etnis Batak, Jawa, Manado, Papua. Mereka tidak membedabedakan antara etnis yang satu dengan lainnya. Mereka sangat menghargai perbedaan yang dimiliki individu atau kelompok lainnya, hal itu dibuktikan mulai dengan cara mereka mengobrol dengan bahasa daerah mereka masing-masing tanpa saling mengejek atau menghina.

Novel Tapak Jejak ini menceritakan tentang perjuangan sosok penulis novel yaitu Fiersa Besari, ia melakukan perjalanan menyusuri Indonesia. Hal itu bertujuan untuk proses pembentukan diri Fiersa sedari kecil hingga berujung menjadi seseorang yang memilih untuk pergi berkelana. Fiersa melakukan perjalanan itu demi ingin memerdekakan Indonesia. Dari hasil penelitian yang telah dilakukan dalam novel Tapak Jejak, ditemukan tujuh nilai-nilai pendidikan karakter yaitu 1) religius, 2) jujur, 3) kreatif, 4) semangat kebangsaan, 5) cinta tanah air, 6) komunikatif dan 7) cinta damai. Novel Tapak Jejak berkisah tentang sebuah karya yang positif bagi siapapun, pada novel ini memiliki nilai-nilai yang membangun dalam kehidupan, semangat untuk terus berusaha, dan tidak mudah menyerah untuk mencapai tujuan.

\section{SIMPULAN}

Berdasarkan hasil penelitian, ditemukan tujuh nilai-nilai pendidikan karakter dalam novel Tapak Jejak karya Fiersa Besari, meliputi 1) religius adalah sikap dan perilaku yang patuh dan menghargai terhadap agama lainnya, 2) jujur adalah perilaku yang menjadikan seseorang untuk bersikap jujur terhadap perkataan, perilaku maupun dalam pekerjaan, 3) kreatif adalah sesuatu yang dilakukan dan berpikir dalam suatu hal untuk menghasilkan cara atau menghasilkan sesuatu baru yang telah dimiliki, 4) semangat kebangsaan adalah cara berpikir, bertindak, dan berwawasan yang mementingkan kemerdekaan bangsa dan negara di atas kepentingan diri sendiri, 5) cinta tanah air adalah sikap dan tindakan dalam mencintai bangsa sendiri dengan mengabdi dan berkorban, memelihara kesatuan dan persatuan, serta melindungi tanah air, 6) komunikatif adalah suatu tindakan yang memperlihatkan suatu sikap dalam bergaul, rasa senang berbicara, dan berkerja sama dengan orang lain, dan 7) cinta damai adalah sikap dan perilaku dalam menghargai suatu perbedaan yang dimiliki individu dan kelompok lain.

\section{DAFTAR PUSTAKA}

Besari, Fiersa. (2019). Tapak Jejak. Jakarta Selatan: Mediakita.

Elner, Nindy, Harris Effendi, and Thahar, Abdurahman. (2018). Nilai-Nilai Pendidikan Dalam Novel Mamak Karya Alwi Wilson. Jurnal Puitika, Vol. 14 (1), 1-13.

Febriana, Noni., Effendi, Harris., Thahar., Ermanto. (2014). Nilai-Nilai Pendidikan Karakter Dalam Novel Rantau Satu Muara Karya Ahmad Fuadi: Tinjauan Sosiologi Sastra. Jurnal Genre (Bahasa, Sastra, dan Pembelajarannya, Vol. 2 (3), 94-106.

Ingsih, Kusni., dkk. (2018). Pendidikan Karater Alat Peraga Edukatif Media Interaktif. Yogyakarta: Penerbit Deepulish.

Irma, Cintya Nurika. (2018). Nilai-Nilai Pendidikan Karakter dalam Novel Ibuk Karya Iwan Setyawan. Jurnal Retorika, Vol. 11 (1), 14-22.

Kementerian Pendidikan Nasional. (2011). Pedoman Pelaksanaan Pendidikan Karakter (Berdasarkan Pengalaman di Satuan Pendidikan Rintisan). Jakarta: Badan Penelitian dan Pengembangan Pusat Kurikulum dan Pembukuan.

Nurgiyantoro, Burhan. (2007). Teori Pengkajian Fiksi. Yogyakarta: Gadjah Mada.

Pusvita, Winda Dewi. (2017). Nilai-nilai Pendidikan Karakter Pada Novel Ayah Karya Andrea Hirata”. Jurnal Leksema, Vol. 2 (1), 51-63.

Rosdiatun. 2018. Model Implementasi Pendidikan Karakter. Gresik: Media Communication.

Sipayung, N. N. S,. Lubis, R. S., Sibagariang, N., \& Matahari, R. M. 2019. "Analisis Pendidikan Nilai Karakter Dalam Novel Bidadari-Bidadari Surga Karya Tere Liye." Jurnal Genre (Bahasa, Sastra, dan Pembelajarannya), Vol. 1:(1), 18-26.

Wardani, Ana., Mawardi, Imam., Jannah, Nasitotul . (2015). Jurnal Tarbiyatuna, Vol. 6 (1), 31-46.

Yulianto, Agus., Nuryati, Iis., Mufti Afrizal. (2020). Analisis Nilai-Nilai Pendidikan Karakter 
Dalam Novel Rumah Tanpa Jendela Karya Asma Nadia. Jurnal Bahasa, Sastra Indonesia, dan Pengajarannya. Vol. 1 (1), 111-124. 